\begin{tabular}{cc|c}
\hline Tar. Bil. Der. & Journal of Agricultural Sciences \\
& $\begin{array}{c}\text { Dergi web sayfası: } \\
\text { www.agri.ankara.edu.tr/dergi }\end{array}$ & Journal homepage: \\
& www.agri.ankara.edu.tr/journal
\end{tabular}

\title{
Effect of Microwave, Infrared and Freeze Drying Methods on Drying Kinetics, Effective Moisture Diffusivity and Color Properties of Turmeric
}

\author{
Onur TAŞKIN ${ }^{a}$, Nazmi İZLİ ${ }^{a}$ \\ ${ }^{a}$ Bursa Uludag University, Faculty of Agriculture, Department of Biosystems Engineering, Bursa, TURKEY
}

\section{ARTICLE INFO}

Research Article

DOI: 10.15832 ankutbd.439434

Corresponding Author: Onur TAŞKIN, E-mail: onurtaskins@gmail.com, Tel: +90 (224) 2941602

Received: 30 June 2018, Received in Revised Form: 30 July 2018, Accepted: 14 September 2018

\begin{abstract}
In the present research, effect of methods that use the microwave $(90,160$ and $350 \mathrm{~W})$, infrared $\left(60,70\right.$ and $\left.80{ }^{\circ} \mathrm{C}\right)$, and freeze drying for turmeric samples on the drying kinetics, effective moisture diffusivity and color were analyzed. Also ten distinct thin layer models of drying were used to predict their kinetics. Depending on the evaluation of the statistical tests, models of Midilli et al and Wang \& Singh models were found the optimum ones for explaining drying characteristics of turmeric. Among the used methods, the fastest and slowest drying time was 65 min with microwave drying $(350 \mathrm{~W})$ and 600 min with freeze drying, respectively. The calculations demonstrate that the maximum effective moisture diffusivity value is obtained in microwave drying $(350 \mathrm{~W})$. Our study shows that although the freeze-drying increases the drying time, it showed closest color results against to fresh samples. In conclusion, microwave, infrared and freeze drying methods applied to turmeric should improve with the combined drying applications.
\end{abstract}

Keywords: Turmeric; Drying kinetics; Effective moisture diffusivity; Color

(C) Ankara Üniversitesi Ziraat Fakültesi

\section{Introduction}

Turmeric is a member of the Zingiberaceae family and genus Curcuma (Singh et al 2010; Gupta et al 2015). It is originated into South Asia and exported to the United States of America, the United Kingdom, the Netherlands, South Africa, Singapore, Saudi Arabia, United Arab Emirates, Japan, and Iran (Mishra et al 2015).

Turmeric comprises three compounds namely bis-dimethoxy curcumin, dimethoxy curcumin, curcumin which is biologically active (Riaz et al 2015). It has various beneficial effects on cardioprotective, hypolipidemic, antibacterial, anti$\mathrm{HIV}$, anti-tumor, anti-carcinogenic and anti-arthritic activities (Prathapan et al 2009). Commercially, it is used as a spice for foodstuff with fresh or as dried. However, dried turmeric price for selling worldwide is influenced by many quality factors (moisture content, color, and phenolic contents) (Hirun et al 2014).

Turmeric rhizomes are dried to avoid deterioration after harvesting (Apintanapong \& Maisuthisakul 2011). Therefore, drying is defining moisture removal process and resolves the 
following problems; improves food stability, lowers shipping weights, minimizes chemical and physical changes in due course of storage, and reduces microbiological activity due to the decrease of the water activity (Laosanguanek et al 2009). To dry distinct food products, various drying methods have been applied. Each one comprises its own advantages and disadvantages. However, some products are heat sensitive. If they remain in high temperature for a significant time, they lose some aroma and flavor.

In the present study, the thin layer fresh cubic turmeric rhizomes were dried with microwave, infrared and freeze methods to specify the impact of distinct methods on the drying characteristics, to identify the most optimal drying model, to figure out effective moisture diffusivity values, and to evaluate the differences color.

\section{Materials and Methods}

\subsection{Drying experiments}

Fresh turmeric were bought from a fruiterer in Bursa province of Turkey. During all experiments of this research, mature and healthy turmeric were chosen. The products were kept at $4 \pm 0.5{ }^{\circ} \mathrm{C}$ temperature levels. Content of moisture on a dry basis at first was confirmed to be 3.99 ( $\mathrm{g}$ water g dry matter $^{-1}$ ) with oven drying method (ED115 Binder, Tuttlingen, Germany) at $105^{\circ} \mathrm{C}$ for 24 hours (Aral $\&$ Beşe 2016). The samples were cut into cubes of $5 \times 5 \times 5 \pm 0.04 \mathrm{~mm}$ by means of a slicer (Nicer Dicer, China). In the course of drying experiments, microwave, infrared, and freeze drying methods were utilized. All experiments were repeated three times.

\subsection{Microwave drying}

For the drying experiment, a microwave oven with 90, 160 and $350 \mathrm{~W}$ output levels (AMW 545, Whirlpool, Italy) was used. Turmeric samples of 25 $\mathrm{g}$ were disposed in a thin layer on revolving circular glass plate with $245 \mathrm{~mm}$ diameter. Loss of moisture in the samples was checked with a $0.01 \mathrm{~g}$ precision digital balance (Radwag, Radom, Poland) in every 2 minutes.

\subsection{Infrared drying}

An infrared dryer (Moc63, Shimadzu, Japan) that radiates electromagnetic radiation ranging from medium to shortwave infrared radiation that has a wavelength between $2 \mathrm{~mm}$ and $3.5 \mathrm{~mm}$. By using the device, parameters about moisture content and temperature were defined directly and they are measured on the display of it. Drying procedure was conducted with $10 \mathrm{~g}$ samples at three levels of radiation power which was regulated to attain final temperatures of 60,70 and $80{ }^{\circ} \mathrm{C}$.

\subsection{Freeze drying}

A freeze dryer (Alpha 1-2 LD Plus, Osterode am Harz, Germany) at $-50{ }^{\circ} \mathrm{C}$ process temperature with $52 \mathrm{~Pa}$ constant pressure was used. The moisture loss of $25 \mathrm{~g}$ turmeric sample was gauged in every 2 hours with $\mathrm{a} \pm 0.01 \mathrm{~g}$ precision digital balance (Radwag, Radom, Poland) in the course of the drying procedure.

\subsection{Mathematical modelling of drying data}

The data on moisture ratio (MR) was coupled to ten thin layer models which are characteristically utilized for modeling of drying curves (Table 1). Values of the moisture ratio were figured out by applying Equation 1 and Equation 2.

$M R=\frac{M_{t}-M_{e}}{M_{o}-M_{e}}$

Above $M_{t}$ stands for the moisture content ( $\mathrm{g}$ water $\mathrm{g}$ dry matter ${ }^{-1}$ ) at a given time, $M_{o}$ stands for the initial moisture content ( $\mathrm{g}$ water $\mathrm{g}$ dry matter ${ }^{-1}$ ), $M_{e}$ stands for the equilibrium moisture content (g water g dry matter ${ }^{-1}$ ). In comparison to $M_{t}$ or $M_{o}, M_{e}$ values are relatively small. As a result, several researchers have vulgarized the moisture ratio as follows (Midilli et al 2002):

$$
M R=\frac{M_{t}}{M_{o}}
$$


Table 1- Thin layer drying models used for the turmeric drying kinetics

\begin{tabular}{|c|c|c|c|}
\hline No & Model name & Model & References \\
\hline 1 & Henderson \& Pabis & $M R=a \exp (-k t)$ & (Westerman et al 1976) \\
\hline 2 & Newton & $M R=\exp (-k t)$ & (Ayensu 1997) \\
\hline 3 & Page & $M R=\exp \left(-k t^{n}\right)$ & (Agrawal \& Singh 1977) \\
\hline 4 & Logarithmic & $M R=a \exp (-k t)+c$ & (Yagcioglu et al 1999) \\
\hline 5 & Two Term & $M R=a \exp \left(-k_{0} t\right)+b \exp \left(-k_{1} t\right)$ & (Madamba et al 1996) \\
\hline 6 & Two Term Exponential & $M R=a \exp (-k t)+(1-a) \exp (-k a t)$ & (Sharaf-Eldeen et al 1980) \\
\hline 7 & Wang \& Singh & $M R=1+a t+b t^{2}$ & (Wang \& Singh 1978) \\
\hline 8 & Diffusion Approach & $M R=a \exp (-k t)+(1-a) \exp (-k b t)$ & (Kassem 1998) \\
\hline 9 & Verma et al & $M R=a \exp (-k t)+(1-a) \exp (-g t)$ & (Verma et al 1985) \\
\hline 10 & Midilli et al & $M R=a \exp \left(-k t^{n}\right)+b t$ & (Midilli et al 2002) \\
\hline
\end{tabular}

\subsection{Determination of effective moisture diffusivity}

According to the $2^{\text {nd }}$ law of Fick on the diffusion Equation, drying of agricultural products with a declining rate during a time frame is symbolized by using a mass-diffusion equation as Equation (3):

$$
\frac{\partial M}{\partial t}=\nabla M\left[\mathrm{D}_{\text {eff }}(\nabla \mathrm{M})\right]
$$

The Equation (3) that explains the $2^{\text {nd }}$ law of Fick on unsteady state diffusion can be utilized to figure out the moisture ratio calculated in Equation (4). For an infinite slab, the formula of diffusion equation was set forth (Crank 1975), and uniform initial moisture distribution, steady diffusivity, immaterial shrinkage, and negligible external resistance were expected:

$$
M R=\frac{8}{\pi^{2}} \sum_{n=0}^{\infty} \frac{1}{(2 n+1)^{2}} \exp \left(-\frac{(2 n+1)^{2} \pi^{2} D_{\text {eff }} t}{4 L^{2}}\right)
$$

Where; $D_{\text {eff }}\left(\mathrm{m}^{2} \mathrm{~s}^{-1}\right)$ stands for effective moisture diffusivity; $t$ (s) stands for time; $L(\mathrm{~m})$ stands for sample's half thickness; $\mathrm{n}$ stands for a positive integer.

Regarding for extend drying periods, only the first term in Equation (4) is significant and consequently, the Equation is simplified as The Equation (5) as logarithmically:

$$
M R=\frac{8}{\pi^{2}} \exp \left(-\frac{\pi^{2} D_{e f f} t}{4 L^{2}}\right)
$$

Plotting experimental drying data from the point of $\ln$ (MR) versus drying period enables to figure out effective moisture diffusivity values in Equation (6). The slope of the straight line which is generated by the plot is calculated as follows (Doymaz et al 2015):

$$
K=\frac{\pi^{2} D_{e f f}}{4 L^{2}}
$$

\subsection{Color measurement}

With the use of a colorimeter (MSEZ-4500L, HunterLab, USA), L*, $a^{*}$, and $b^{*}$ values of dried and fresh turmeric samples were classified in ten readings that are realized at random positions on the surfaces of samples. The color parameters, $L_{0}{ }^{*}, a_{0}{ }^{*}$ and $b_{0}{ }^{*}$ of the fresh turmeric samples. Throughout these experiments, before every color determination, white-black plates were used for calibration of the colorimeter. First of all, a glass cell that contains a sample was disposed above the light source that is near the nose cone of the colorimeter and then the 
values of the parameters $L_{0}{ }^{*}, a_{0}{ }^{*}, b_{0}{ }^{*}, L^{*}, a^{*}$, and $b^{*}$ were saved. Moreover, the Chroma $C$, hue angle $\alpha$, and the overall color difference $\Delta \mathrm{E}$ was calculated in Equation (7), Equation (8) and Equation (9), respectively (Delgado et al 2016).

$$
\begin{aligned}
& C=\sqrt{\left(a^{2}+b^{2}\right)} \\
& \alpha=\tan ^{-1}\left(\frac{b}{a}\right) \\
& \Delta E=\sqrt{\left(L_{0}^{*}-L^{*}\right)^{2}+\left(a_{0}^{*}-a^{*}\right)^{2}+\left(b_{0}^{*}-b^{*}\right)^{2}}
\end{aligned}
$$

\subsection{Statistical analysis}

The research was carried out with the help of randomized plots factorial design. During the measurement process of the inspected products, three replicates were utilized. For analyzing the obtained results, JMP (Version 7.0, SAS Institute Inc., Cary, NC, USA) and MATLAB (MathWorks Inc., Natick, MA) technologies were utilized. For significance, testing of mean differences was performed and the least significant difference test (LSD) yielded level of $5 \%$ significance. The optimum model that describes drying characteristics of turmeric sample in a thin layer is verified as the one that has the maximum coefficient of determination $\left(R^{2}\right)$ and the lowest reduced chi-squared $\left(\chi^{2}\right)$ and the lowest root mean square error (RMSE) values (Arumuganathan et al 2009). The mentioned statistical values are described as below:

$\chi^{2}=\frac{\sum_{i=1}^{N}\left(M R_{\exp , i}-M R_{p r e, i}\right)^{2}}{N-z}$

$R M S E=\sqrt{\frac{\sum_{i=1}^{N}\left(M R_{p r e, i}-M R_{\exp , i}\right)}{N}}$

Where; $M R_{\text {exp }, i}$, stands for the experimental moisture ratio for test number I; $M R_{\text {pre, },}$, stands for the estimated moisture ratio for test number i; $N$ stands for the number of observation and $z$ stands for the count of constants in the drying model (Doymaz \& Ismail 2011).

\section{Results and Discussion}

\subsection{Drying kinetics of turmeric}

The drying curves of turmeric samples that were dried via different drying methods are depicted in Figure 1. It is clear that the drying method significantly influenced to achieve the final moisture content in terms of total drying time. Among the used drying methods in this study, longest period was realized with freeze drying (600 $\mathrm{min})$ and microwave drying at $350 \mathrm{~W}$ (65 min) application took shortest period. These results indicated that with respect to the freezedrying method when the turmeric samples were dried at $350 \mathrm{~W}$ microwave power, drying period declined by $89.17 \%$. Additionally, a remarkable decline took place in the drying period when the microwave level has risen. Accordingly, the drying periods were 255,125 and $65 \mathrm{~min}$ for the samples that were dried at 90, 120 and $350 \mathrm{~W}$, respectively. Similarly, the decline in drying periods along with the rise in the microwave power level has also been confirmed for okra (Dadal1 et al 2007), pumpkin (Wang et al 2007), white mulberry (Evin 2011) and onion slices (Arslan \& Özcan 2010). As expected, the shortest time in infrared drying (120 min) was obtained at $80^{\circ} \mathrm{C}$ in comparison with 60 and $70{ }^{\circ} \mathrm{C}$, which required times of 250 and 170 min, respectively. Thus, an important decrease in the drying period has been realized as drying temperature rises. Identical results were recorded for various samples under infrared dryings, such as apple (Toğrul 2005), wet olive husk (Celma et al 2008), and tomato (Sadin et al 2014).

\subsection{Fitting of drying curves}

Tables 2-3 denote the statistical analysis values obtained from the nonlinear regression of the all thin layer drying models including the comparison criteria and the drying model coefficients that 


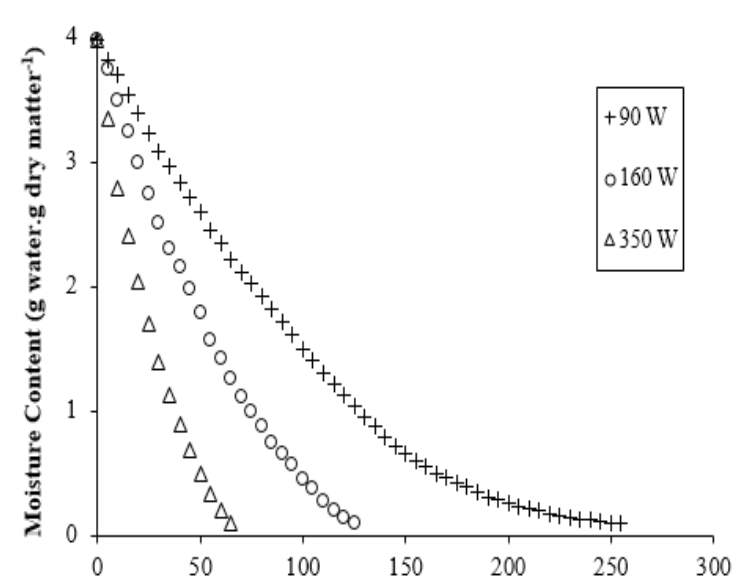

a)

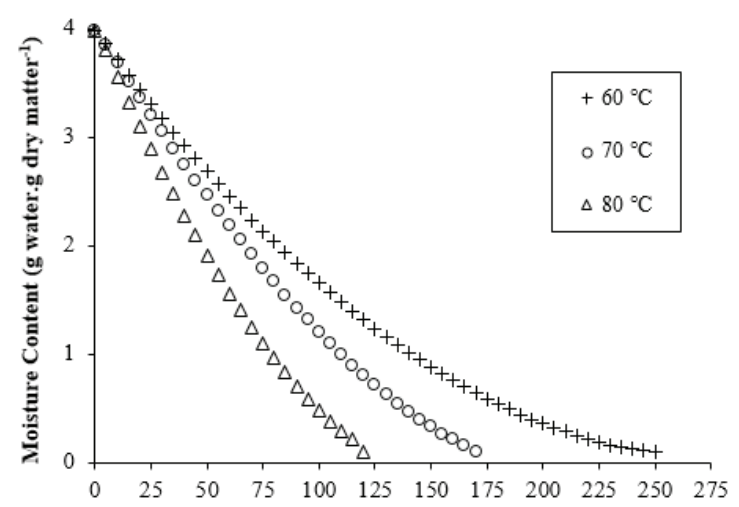

b)

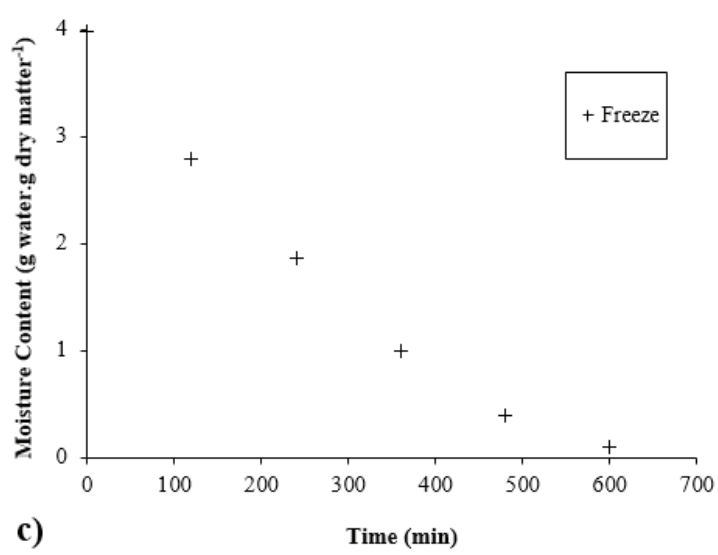

Figure 1- Drying curves of turmeric samples; microwave powers (a), infrared temperatures (b) and freeze (c) are benefited to assess the suitability quality, $R^{2}$, $R M S E$, and $\chi^{2}$. In all cases, The $R^{2}$ values ranged from 0.9606 to 0.9999 , RMSE values ranged from 0.0027 to 0.0597 and $\chi^{2}$ values ranged from $0.0807 \times 10^{-4}$ to $35.9287 \times 10^{-4}$, that are pointing out good fit results. The Midilli et al model put forward more suitable statistical values as against the other models for 70 and $80{ }^{\circ} \mathrm{C}$ the infrared temperatures and for 160 and $350 \mathrm{~W}$ microwave power levels. Furthermore, the Wang \& Singh model demonstrated greater $R^{2}$ value and smaller $R M S E$ and $\chi^{2}$ values as against other thin-layer drying models at $60{ }^{\circ} \mathrm{C}$ infrared temperature, 90 $\mathrm{W}$ microwave power level, and freeze condition. In the Midilli et al and the Wang \& Singh models, values of the $R^{2}, R M S E$ and $\chi^{2}$ varied between 0.9985 and $0.9999,0.0027$ and $0.0146,0.0807 \times 10^{-4}$ and $3.4160 \times 10^{-4}$; and also 0.9963 and 0.9999 , 0.0031 and $0.0189,0.0864 \times 10^{-4}$ and $3.9596 \times 10^{-4}$, in return. Based on these outcomes, the Midilli et al and Wang \& Singh models might be accepted as demonstrating the thin-layer drying behavior of the turmeric samples.

Figure 2 demonstrates the variance between the most appropriate predicted models and experimental moisture ratio at selected drying conditions for dried turmeric. Obviously, the results obtained from the models of Midilli et al and Wang $\&$ Singh are quite close to the experimental values. So it may be deduced that Midilli et al and Wang \& Singh models may identify the drying curves of turmeric samples properly. The outcomes of this study are in line with earlier ones found in the drying of rough rice (Cihan et al 2007), olive pomace (Smail Meziane 2011) and mushroom (Motevali et al 2011) for the Midilli et al model and bamboo shoot (Bal et al 2010), banana (Kadam \& Dhingra 2011) and paddy (Manikantan et al 2014) for Wang \& Singh model.

\subsection{Determination of effective moisture diffusivity}

The determined effective moisture diffusivity values for cubic turmeric rhizomes are demonstrated in Table 4 and were ranged between $1.01 \times 10^{-9}$ and $9.12 \times 10^{-9} \mathrm{~m}^{2} \mathrm{~s}^{-1}$. It may be observed that $\mathrm{D}_{\text {eff }}$ values 


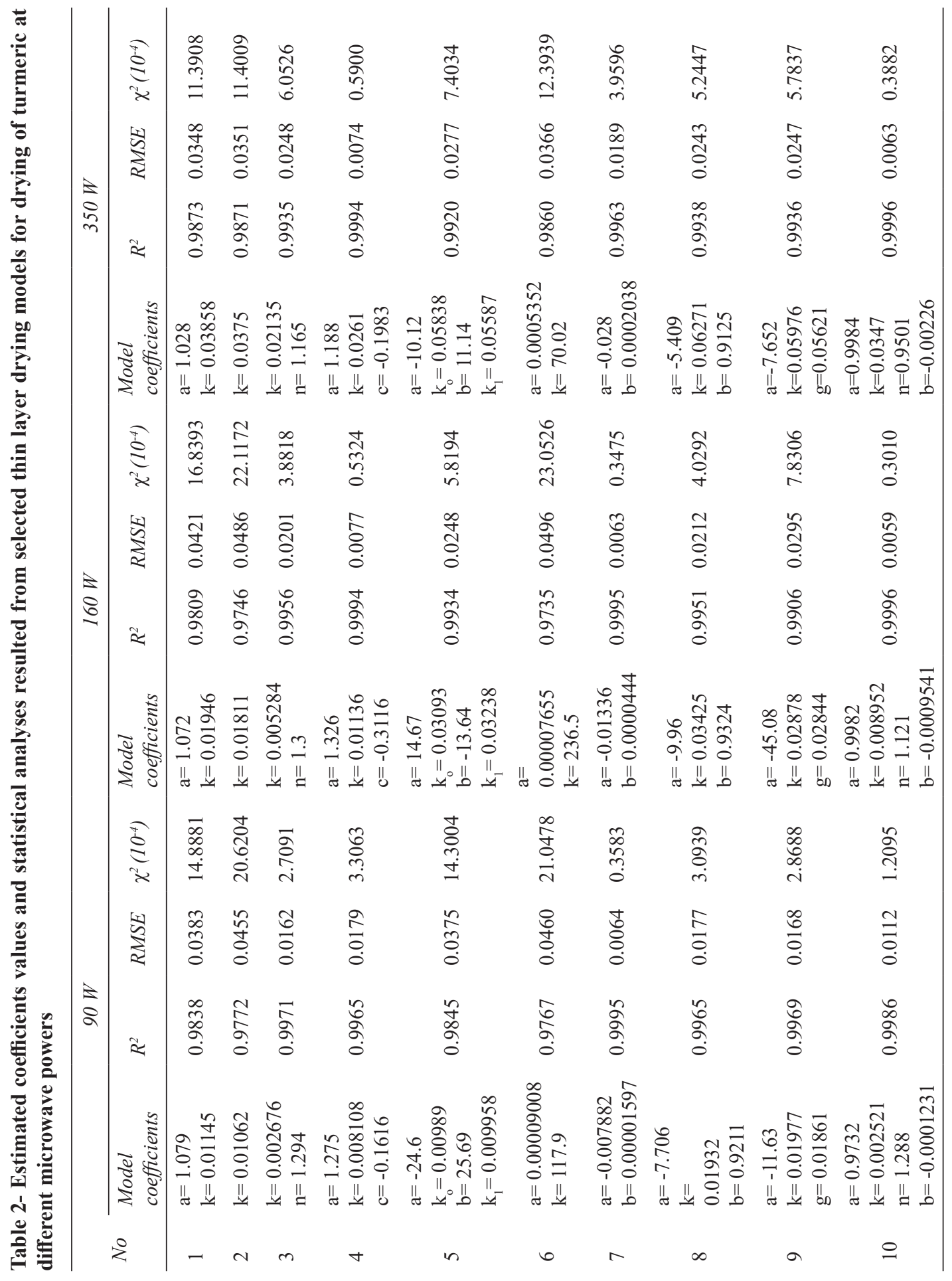




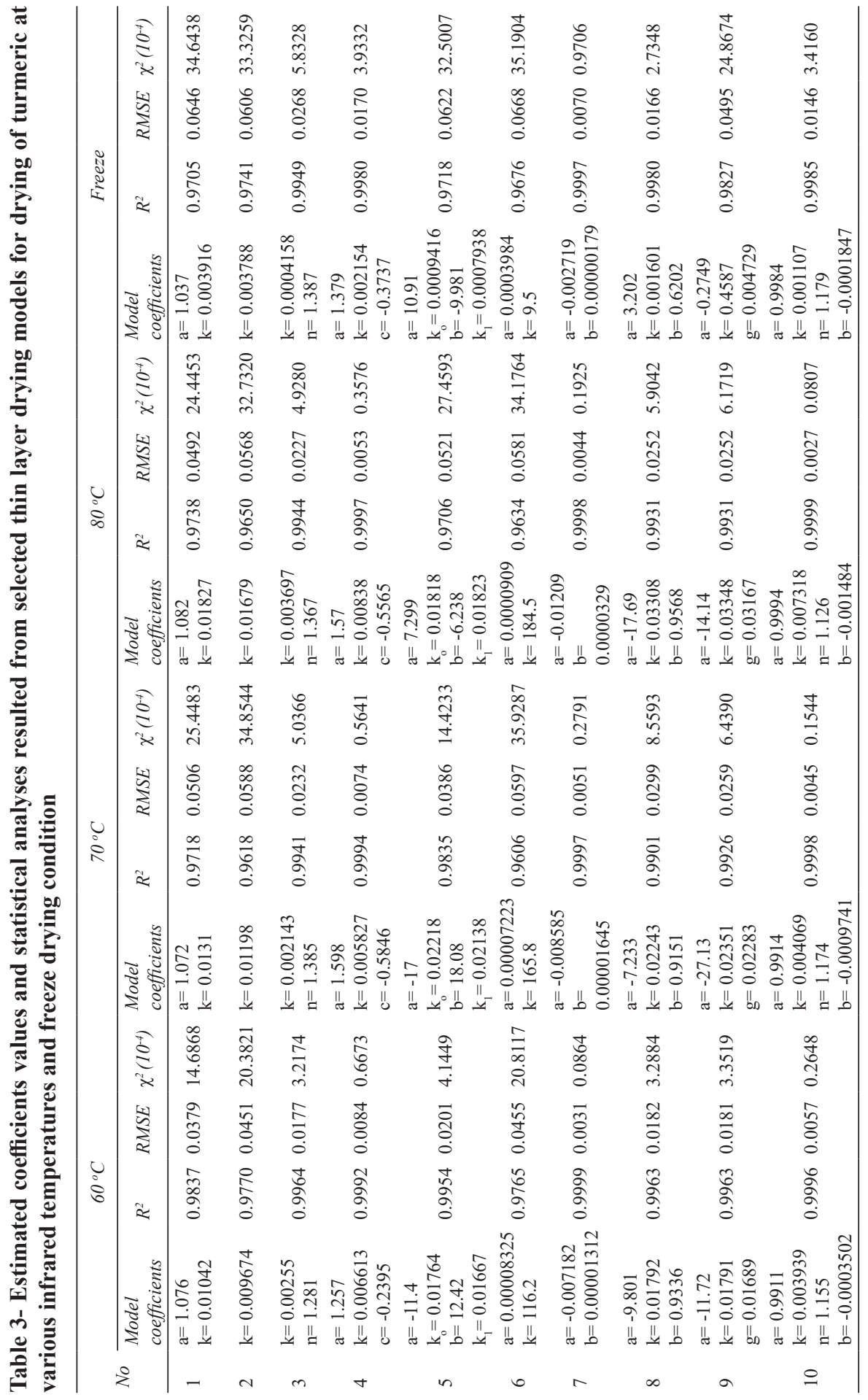




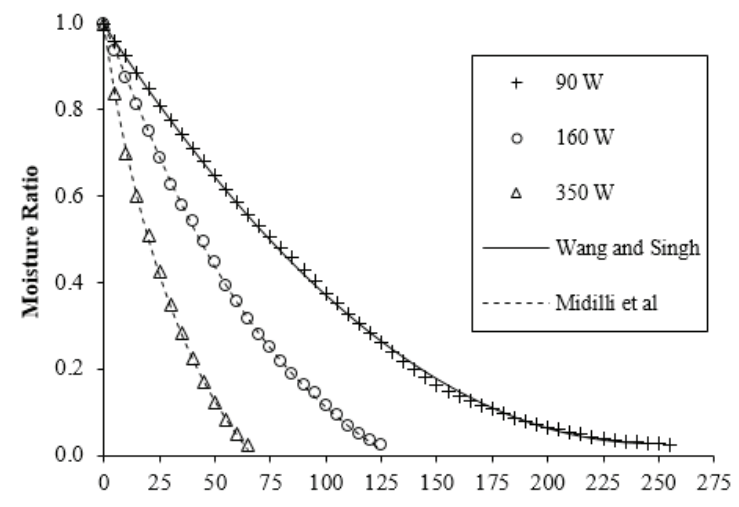

a)

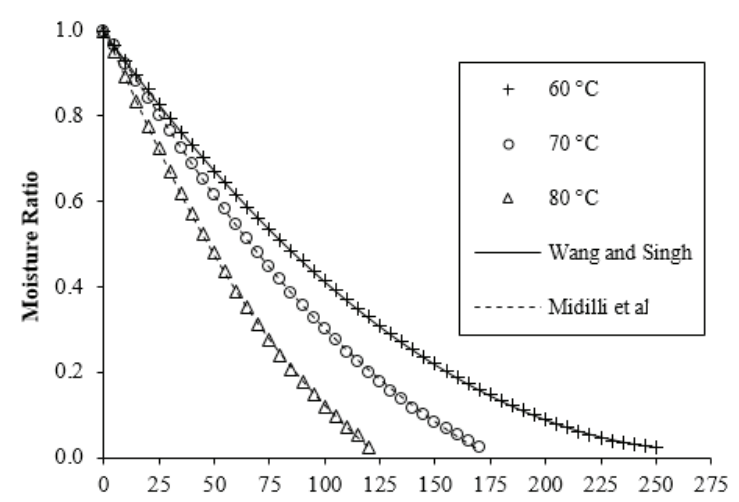

b)

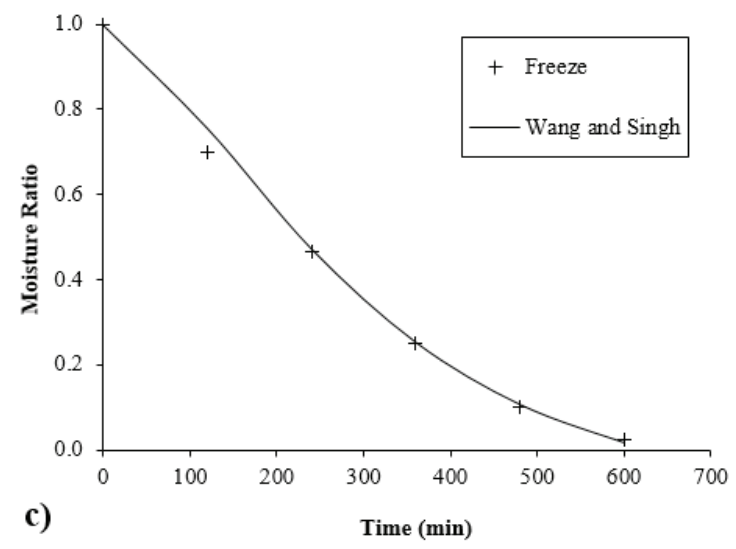

Figure 2- A comparison of the appropriate models to experimental moisture ratios at specific drying times under microwave (a), infrared (b) and freeze (c) drying conditions have risen significantly with rising infrared radiation and microwave power. During drying, the effective moisture diffusivity value is at its maximum level at $350 \mathrm{~W}$ power levels and its lowest level is yielded at freeze-drying. This can be explained by the rapid of vapor pressure. These diffusivity values were good agreement with reported for turmerics such as drying of sliced and solid turmeric with solar conduction dryer which was found $1.852 \times 10^{-10}$ and $1.456 \times 10^{-10} \mathrm{~m}^{2} \mathrm{~s}^{-1}$, respectively (Borah et al 2015), and $8.43 \times 10^{-11}$ to $2.51 \times 10^{-10} \mathrm{~m}^{2} \mathrm{~s}^{-1}$ for drying at $50^{\circ} \mathrm{C}$ hot air temperature in a tray drier (Parveen et al 2013). Also, the effective moisture diffusivities at 60,80 and $100{ }^{\circ} \mathrm{C}$ of blanched rhizomes and unblanched rhizomes for cylinder were $3.23 \times 10^{-10}$, $6.10 \times 10^{-10}, \quad 10.90 \times 10^{-10} \mathrm{~m}^{2} \mathrm{~s}^{-1}$ and $1.77 \times 10^{-10}$, $3.73 \times 10^{-10}, 7.80 \times 10^{-10} \mathrm{~m}^{2} \mathrm{~s}^{-1}$, respectively. Similar values for slab were found $11.90 \times 10^{-10}, 19.60 \times 10^{-10}$, $35.10 \times 10^{-10} \mathrm{~m}^{2} \mathrm{~s}^{-1}$ and $6.87 \times 10^{-10}, 14.05 \times 10^{-10}$, $28.00 \times 10^{-10} \mathrm{~m}^{2} \mathrm{~s}^{-1}$, respectively (Blasco et al 2005). These values mentioned above are in concordance with the estimated $\mathrm{D}_{\text {eff }}$ values that are provided for dried turmeric with infrared, microwave and freeze dryers.

Table 4- Effective moisture diffusivities of dried turmeric samples

\begin{tabular}{ll}
\hline Drying method & $D_{\text {eff }}\left(\mathrm{m}^{2} \mathrm{~s}^{-1}\right)$ \\
\hline Microwave drying & \\
$90 \mathrm{~W}$ & $2.03 \times 10^{-9}$ \\
$160 \mathrm{~W}$ & $4.05 \times 10^{-9}$ \\
$350 \mathrm{~W}$ & $9.12 \times 10^{-9}$ \\
Infrared drying & \\
$60{ }^{\circ} \mathrm{C}$ & $2.03 \times 10^{-9}$ \\
$70{ }^{\circ} \mathrm{C}$ & $3.04 \times 10^{-9}$ \\
$80{ }^{\circ} \mathrm{C}$ & $4.05 \times 10^{-9}$ \\
Freeze drying & $1.01 \times 10^{-9}$ \\
\hline
\end{tabular}

\subsection{Color analysis}

Color reflects the quality of the dried product samples also it is a determinant of the consumer acceptance. The results concerning the color changes of the fresh turmeric samples and the dried ones throughout distinct drying methods are detailed in Table 5. Drying methods significantly 
$(\mathrm{P}<0.05)$ affected color values of turmeric. Regarding lightness, freeze-dried turmeric promoted an increase in $L^{*}$ values $\left(L^{*}=46.19\right.$ for the fresh sample). In other respects, the fresh turmeric sample (38.42) possessed significantly higher $a^{*}$ values $(\mathrm{P}<0.05)$ in comparison to every other drying methods. The $b^{*}$ value was significantly at its maximum level $(\mathrm{P}<0.05)$ for the freeze-dried sample (66.04) and the lowest for an infrared dried sample at 60 and $70{ }^{\circ} \mathrm{C}$. Further, the maximum $C$ value was obtained with 72.53 in freeze-dried and significantly more vivid $(\mathrm{P}<0.05)$ with regard to color as against all other fresh samples and dried ones. In contrast with the sample of fresh, a significant increase $(\mathrm{P}<0.05)$ was seen in $\alpha$ value of in all dried samples. Infrared-dried turmeric showed a significantly different $\Delta E$ value $(\mathrm{P}<0.05)$ at 35.56 and 36.13 (60 and $70{ }^{\circ} \mathrm{C}$, respectively) than freeze-dried turmeric at 12.65, perhaps due to presence of polyphenol oxidase (PPO) and/or peroxidase (POD) compounds that reacted with phenolic to form browning mechanism (Hirun et al 2014) were observed that during infrared drying. Color changes of turmeric in the various drying methods have been reported that color quality of turmeric is more dependent quality attributes than every other and an active ingredient of turmeric (curcumin) is photosensitive and highly responsible for its color (Borah et al 2017). The study of Hirun et al (2014), found that products might remain brighter in color when increasing microwave-vacuum power up to $4000 \mathrm{~W}$. Similarly, hot air drying method culminated in less red color (low $a^{*}$ value) and a darker color (lower $L^{*}$ value) as against the combined microwave vacuum drying. However, this drying method yielded in higher yellow color value (Apintanapong \& Maisuthisakul 2011).

Table 5- Color values of dried and fresh turmeric samples

\begin{tabular}{lcccccc}
\hline \multirow{2}{*}{ Drying method } & \multicolumn{5}{c}{ Color parameters } \\
\cline { 2 - 7 } & $L^{*}$ & $a^{*}$ & $b^{*}$ & $C$ & $\alpha^{\circ}$ & $\Delta E$ \\
\hline Fresh & $46.62 \pm 2.43^{\mathrm{b}}$ & $38.42 \pm 1.21^{\mathrm{a}}$ & $58.38 \pm 1.82^{\mathrm{b}}$ & $69.89 \pm 2.18^{\mathrm{b}}$ & $56.68 \pm 0.06^{\mathrm{a}}$ & - \\
Microwave drying & & & & & & \\
$90 \mathrm{~W}$ & $32.10 \pm 1.04^{\mathrm{c}}$ & $22.60 \pm 0.71^{\mathrm{d}}$ & $36.23 \pm 1.03^{\mathrm{d}}$ & $42.70 \pm 1.24^{\mathrm{d}}$ & $58.07 \pm 0.18^{\mathrm{d}}$ & $30.85 \pm 1.58^{\mathrm{c}}$ \\
$160 \mathrm{~W}$ & $32.66 \pm 0.34^{\mathrm{c}}$ & $24.90 \pm 0.30^{\mathrm{c}}$ & $40.00 \pm 0.21^{\mathrm{c}}$ & $47.12 \pm 0.33^{\mathrm{c}}$ & $58.14 \pm 0.20^{\mathrm{d}}$ & $26.75 \pm 0.42^{\mathrm{b}}$ \\
$350 \mathrm{~W}$ & $32.29 \pm 0.13^{\mathrm{c}}$ & $25.14 \pm 0.40^{\mathrm{c}}$ & $36.65 \pm 0.33^{\mathrm{c}}$ & $46.95 \pm 0.30^{\mathrm{c}}$ & $57.56 \pm 0.52^{\mathrm{c}}$ & $27.07 \pm 0.29^{\mathrm{b}}$ \\
Infrared drying & & & & & & \\
$60^{\circ} \mathrm{C}$ & $29.52 \pm 0.58^{\mathrm{d}}$ & $20.72 \pm 0.60^{\mathrm{f}}$ & $32.71 \pm 0.78^{\mathrm{f}}$ & $38.72 \pm 0.98^{\mathrm{f}}$ & $57.67 \pm 0.19^{\mathrm{c}}$ & $35.57 \pm 1.12^{\mathrm{e}}$ \\
$70^{\circ} \mathrm{C}$ & $29.85 \pm 0.57^{\mathrm{d}}$ & $20.07 \pm 0.26^{\mathrm{g}}$ & $32.15 \pm 0.48^{\mathrm{f}}$ & $37.90 \pm 0.52^{\mathrm{f}}$ & $58.04 \pm 0.23^{\mathrm{d}}$ & $36.13 \pm 0.71^{\mathrm{e}}$ \\
$80^{\circ} \mathrm{C}$ & $29.62 \pm 0.78^{\mathrm{d}}$ & $22.00 \pm 0.49^{\mathrm{e}}$ & $34.00 \pm 0.50^{\mathrm{e}}$ & $40.50 \pm 0.68^{\mathrm{e}}$ & $57.13 \pm 0.25^{\mathrm{b}}$ & $33.96 \pm 0.96^{\mathrm{d}}$ \\
Freeze drying & $51.99 \pm 1.15^{\mathrm{a}}$ & $30.00 \pm 0.78^{\mathrm{b}}$ & $66.04 \pm 0.94^{\mathrm{a}}$ & $72.54 \pm 1.06^{\mathrm{a}}$ & $65.61 \pm 0.49^{\mathrm{e}}$ & $12.65 \pm 0.94^{\mathrm{a}}$ \\
\hline
\end{tabular}

${ }^{\mathrm{a}-\mathrm{g}}$, in a column, means within the different letters are significantly different $(\mathrm{P}<0.05)$

\section{Conclusions}

In conclusion, various methods could be used as a drying opportunity of turmeric. When the drying methods utilized in this research are compared, microwave drying reduced the drying period significantly as against the infrared and freeze methods. However, the best and worst color results are achieved with freeze and infrared methods, respectively. Among the applied drying models, it is found that the Midilli et al and the Wang \& Singh models are the most appropriate ones to clarify the drying kinetics of turmeric samples. Further understanding of turmeric drying will be important for the dried food industry to gain a new perspective. 


\begin{tabular}{|ll|}
\hline Abbreviations and Symbols \\
\hline$M_{0}$ & Initial moisture content, $\mathrm{g}$ water $\mathrm{g}$ dry matter $^{-1}$ \\
$M_{t}$ & The moisture content at a particular time, $\mathrm{g}$ water $\mathrm{g}$ dry matter \\
$M_{e}$ & Equilibrium moisture content, $\mathrm{g}$ water $\mathrm{g}$ dry matter $^{-1}$ \\
$M R_{\text {exp }, i}$ & Experimental moisture ratio at the test number i, \\
$M R_{p r e, i}$ & Estimated moisture ratio at the test number $\mathrm{i}$, \\
$N$ & Observation number \\
$z$ & Total count of constant \\
$R M S E$ & Root mean square error \\
$R^{2}$ & Coefficient of determination \\
$\chi^{2}$ & Reduced chi-square \\
$a, b, c, g, n, k_{o}, k_{l}$ & Model constants \\
$D_{e f f}$ & Effective moisture diffusivity \\
$t$ & Stands for time \\
$L^{*}$ & Whiteness/Darkness \\
$a^{*}$ & Redness/Greenness \\
$b^{*}$ & Yellowness/Blueness \\
$C$ & Chroma \\
$\alpha$ & Hue angle \\
$\Delta E$ & Total color differences \\
$L_{0}{ }^{*}$ & Whiteness/Darkness of fresh sample \\
$a_{0}{ }^{*}$ & Fresh sample of fresh sample \\
$b_{0}{ }^{*}$ & Fresh sample of fresh sample \\
& \\
\hline
\end{tabular}

\section{References}

Agrawal Y C \& Singh R P (1977). Thin-layer drying studies on short-grain rough rice. Paper No: 3531, ASAE, St. Joseph, MI

Apintanapong M \& Maisuthisakul P (2011). Microwavevacuum drying kinetics of turmeric. Agricultural Science Journal (Thailand) 42(2): 269-272

Aral S \& Beşe A V (2016). Convective drying of hawthorn fruit (Crataegus spp.): effect of experimental parameters on drying kinetics, color, shrinkage, and rehydration capacity. Food Chemistry 210: 577-584

Arslan D \& Özcan M M (2010). Study the effect of sun, oven and microwave drying on quality of onion slices. LWT-Food Science and Technology 43(7): 1121-1127

Arumuganathan T, Manikantan M R, Rai R D, Anandakumar S \& Khare V (2009). Mathematical modeling of drying kinetics of milky mushroom in a fluidized bed dryer. International Agrophysics 23(1): 1-7

Ayensu A (1997). Dehydration of food crops using a solar dryer with convective heat flow. Solar Energy 59(4): 121-126

Bal L M, Kar A, Satya S \& Naik S N (2010). Drying kinetics and effective moisture diffusivity of bamboo shoot slices undergoing microwave drying. International Journal of Food Science \& Technology 45: 2321-2328

Blasco M, García-Pérez J V, Bon J, Carreres J E \& Mulet A (2005). Effect of blanching and air flow rate on turmeric drying. Food Science and Technology International 12(4): 315-323

Borah A, Hazarika K \& Khayer S M (2015). Drying kinetics of whole and sliced turmeric rhizomes (Curcuma longa L.) in a solar conduction dryer. Information Processing in Agriculture 2(2): 85-92 
Borah A, Sethi L N, Sarkar S \& Hazarika K (2017). Effect of drying on texture and color characteristics of ginger and turmeric in a solar biomass integrated dryer. Journal of Food Process Engineering 40(1): $1-6$

Celma A R, Rojas S \& Lopez-Rodriguez F (2008). Mathematical modelling of thin-layer infrared drying of wet olive husk. Chemical Engineering and Processing: Process Intensification 47: 1810-1818

Cihan A, Kahveci K \& Hacihafzoğlu O (2007). Modeling of intermittent drying of thin layer rough rice. Journal of Food Engineering 79(1): 293-298

Crank J (1975). The mathematics of diffusion. $2^{\text {nd }}$ edition, Oxford University Press, London

Dadalı G, Kılıç Apar D \& Özbek B (2007). Microwave drying kinetics of okra. Drying Technology 25(5): 917-924

Delgado T, Pereira J A, Casal S \& Ramalhosa E (2016). Effect of drying on color, proximate composition and drying kinetics of sliced chestnuts. Journal of Food Process Engineering 39(5): 512-520

Doymaz I \& Ismail O (2011). Drying characteristics of sweet cherry. Food and Bioproducts Processing 89(1): 31-38

Doymaz I, Kipcak A S \& Piskin S (2015). Microwave drying of green bean slices: drying kinetics and physical quality. Czech Journal of Food Science 33(4): 367-376

Evin D (2011). Microwave drying and moisture diffusivity of white mulberry: experimental and mathematical modeling. Journal of Mechanical Science and Technology 25(10): 2711-2718

Gupta A K, Mishra R \& Lal R K (2015). Genetic resources, diversity, characterization and utilization of agronomical traits in turmeric (Curcuma longa L.). Industrial Crops and Products 77: 708-712

Hirun S, Utama-ang N \& Roach P D (2014). Turmeric (Curcuma longa L.) drying: an optimization approach using microwave-vacuum drying. Journal of Food Science and Technology 51(9): 2127-2133

Kadam D M \& Dhingra D (2011). Mass transfer kinetics of banana slices during osmo-convective drying. Journal of Food Process Engineering 34(2): 511-532

Kassem A S (1998). Comparative studies on thin layer drying models for wheat. In: Proceedings of the $13^{\text {th }}$ International Congress on Agricultural Engineering, 2-6 February, Morocco, vol. 6
Laosanguanek N, Assawarachan R \& Noomhorm A (2009). Thin layer infrared radiation drying of turmeric slices. In: International Agricultural Engineering Conference, 7-10 December, Bangkok, pp. 1-12

Madamba P S, Driscoll R H \& Buckle K A (1996). The thin-layer drying characteristics of garlic slices. Journal of Food Engineering 29(1): 75-97

Manikantan M R, Barnwal P \& Goyal R K (2014). Drying characteristics of paddy in an integrated dryer. Journal of Food Science and Technology 51(4): 813-819

Midilli A, Kucuk H \& Yapar Z (2002). A new model for single layer drying. Drying Technology 20(7): 15031513

Mishra R, Gupta A K, Lal R K, Jhang T \& Banerjee $N$ (2015). Genetic variability, analysis of genetic parameters, character associations and contribution for agronomical traits in turmeric (Curcuma longa L.). Industrial Crops and Products 76: 204-208

Motevali A, Minaei S, Khoshtaghaza M H \& Amirnejat $H$ (2011). Comparison of energy consumption and specific energy requirements of different methods for drying mushroom slices. Energy 36: 6433-6441

Parveen S, Kailappan R \& Dhananchezhiyan P (2013). Studies on shrinkage of turmeric rhizomes during drying. International Journal of Food Nutrition and Science 2: 30-34

Prathapan A, Lukhman M, Arumughan C, Sundaresan A \& Raghu K G (2009). Effect of heat treatment on curcuminoid, colour value and total polyphenols of fresh turmeric rhizome. International Journal of Food Science \& Technology 44: 1438-1444

Riaz M R, Rauf S A, Lupoli R, Rafi M A, Jilani G \& Siddiqi A R (2015). Potential of turmeric extract and its fractions to control peach fruit fly (Diptera: Tephritidae). Ciência e Agrotecnologia 39(6): 545552

Sadin R, Chegini G R \& Sadin H (2014). The effect of temperature and slice thickness on drying kinetics tomato in the infrared dryer. Heat and Mass Transfer 50: 501-507

Sharaf-Eldeen Y I, Blaisdell J L \& Hamdy M Y (1980). A model for ear corn drying. Transactions of the ASAE 23(5): 1261-1265

Singh G, Arora S \& Kumar S (2010). Effect of mechanical drying air conditions on quality of turmeric powder. Journal of Food Science and Technology 47(3): 347350 
Smail Meziane S (2011). Drying kinetics of olive pomace in a fluidized bed dryer. Energy Conversion and Management 52(3): 1644-1649

Toğrul H (2005). Simple modeling of infrared drying of fresh apple slices. Journal of Food Engineering 71: 311-323

Verma L R, Bucklin R A, Endan J B \& Wratten F T (1985). Effects of drying air parameters on rice drying models. Transactions of the ASAE 28(1): 296-301

Wang C Y \& Singh R P (1978). Use of variable equilibrium moisture content in modeling rice drying. Transactions of the ASAE 11(6): 668-672
Wang J, Wang J S \& Yu Y (2007). Microwave drying characteristics and dried quality of pumpkin. International Journal of Food Science \& Technology 42(2): 148-156

Westerman P W, White G M \& Ross I J (1976). Relative humidity effect on the high-temperature drying of shelled corn. Transactions of the ASAE 16(6): 11361139

Yagcioglu A, Degirmencioglu A \& Cagatay F (1999). Drying characteristics of laurel leaves under different drying conditions. In: Proceedings of the $7^{\text {th }}$ International Congress on Agricultural Mechanization and Energy, 26-27 May, Adana, pp. 565-569 